\title{
Dynamic Nexus between Air-Transportation and Economic Growth: A Systematic Literature Review
}

\author{
Ruwan Higgoda', M. W. Madurapperuma² \\ ${ }^{1}$ Airport \& Aviation Services (Sri Lanka) Limited, Colombo, Sri Lanka \\ ${ }^{2}$ Department of Accountancy, University of Kelaniya, Kelaniya, Sri Lanka \\ Email: ruwanatc.ans@airport.lk,wasanthi@kln.ac.lk
}

How to cite this paper: Higgoda, R. and Madurapperuma, M.W. (2019) Dynamic Nexus between Air-Transportation and Economic Growth: A Systematic Literature Review. Journal of Transportation Technologies, 9, 156-170.

https://doi.org/10.4236/jtts.2019.92010

Received: December 31, 2018

Accepted: April 5, 2019

Published: April 8, 2019

Copyright $\odot 2019$ by author(s) and Scientific Research Publishing Inc. This work is licensed under the Creative Commons Attribution International License (CC BY 4.0).

http://creativecommons.org/licenses/by/4.0/

\begin{abstract}
Today's economic growth is not promising without air transport, up-to-date airports infrastructure, efficient and safe airline services and international air transport networks. According to WB [1], 40\% of the world-wide tourists travel by air transport. The main aim of this study is to analyze the literatures of air transport and economic growth study. A systematic literature review (SLR) method was used in order to examine related articles from ABDC list journals which are ranked on $A^{*}$, A or B, published in period 1992-2018. This study gives a summary of the trends and research themes which have been identified. Key scholars, as well as their approaches and locations and citations are also mapped. The findings of this study show that there is a growing interest in researching and publishing on Air transportation and economic growth. This study fills a deficiency in specialized literature concerning air transportation in developing countries and provides a foundation for future research in the field of air transportation.
\end{abstract}

\section{Keywords}

Air Transport, Airport, Aviation, Economic Growth, Tourism Growth, Systematic Literature Review

\section{Introduction}

Air transport and economic growth are highly connected and in many cases overlap. Ample studies have shown that air transportation is a significant factor as well as an indicator of economic growth and development. Air transport activity may influence via diverse channels on economic growth. The key point is that air transport is one of major foreign exchange sources [2]. Secondly, air 
transport plays an important role in promoting investments in new infrastructure. Thirdly, given the complex mix of transport-related sectors air transport encourages other industries directly, indirectly and induced manner. The International Air Transport Association has worked with and commissioned Oxford Economics in the year 2012 and shows the benefits generated for the economic as well as social aspects of aviation spanning more than 80 countries globally. The analysis has showed that aviation contributes to gross domestic product (GDP), employment and government tax revenues generated by the sector and its supply chain. Fourth, researchers [3] [4] pointed out that air transport contributes to the employment and the GDP of the country. Fifth, air transport causes economies of scale that boost a country's competitiveness, and finally, air transport is a significant factor in the technical knowledge diffusion. According to Air Transport Action Group report, aviation plays a vital role in facilitating economic growth, mainly in developing countries. Abundant researches [5] [6] [7] [8] show that air transportation may have significant positive impact on economic growth and development. Instead, the studies show that economic development also has had a substantial impact in air transport demand [9] [10]. Subsequently, the issue arises is that whether air transportation promotes economic development and growth, or vice versa, or whether they boost each other. The motivation of this study is to contribute to ongoing research on the reciprocal and complex relationships between air transport and economic development. It is generally acknowledged that air transport contributes to the economic development in countries and regions. Hence, just like other transport infrastructure investments such as road and rail transport, it is therefore a quite often used policy instrument to stimulate economic growth and development [11]. Air transport does not only contribute to the economic welfare of individuals [12] [13] [14] and the productivity level of companies through the provision of better connectivity and enlarged markets [15], but it can also stimulate trade [16] and is indispensable for tourism [17]. Government plays a vital role in this relationship since government policies can influence both economic and air transportation attributes through guidelines and infrastructure investment. Therefore, the objectives of this study are:

- To understand the development of the academic publications related to air transportation and economic growth during the period of 1992-2018.

- To find an overview of the key journals which examine the air transportation and growth.

- To recognize the most frequently cited academic articles and their corresponding theme.

- To determine the relationship between air transportation and growth among the different researchers.

- To show and analyze the country of origin of the related articles.

The main contribution of this paper is to explain and disseminate what has been said by the existing scholars about air transportation and growth in recent decades, the literatures that stand out and the relationship that the authors 
pointed out. This paper provides a foundation for future researchers in the field of air transportation.

The paper is organized as follows: Section two describes the theoretical role of transport in the economy, Section three gives a brief overview of the different approaches that have been used to measure the economic impact of transport, Section four reviews the most important academic papers and research reports which have considered the topic over the last 30 years; Section five presents a summary and conclusions.

\section{Literature/Theoretical Underpinning}

The air transport turns into vital impact to the performance of business and industry by providing air access for companies that must meet the demands and supply, competition and expansion to the world. Many academics and organizations tried to explain the impacts of air transportation on economic growth. However, most of the studies [18] [19] [20] showed that there is a direct, indirect, induced, and catalytic impacts of air transportation to the economic growth. In this study, this categorization has been also considered and further discussed. The most important economic contribution of Air transportation industry is through its impact on the performance of other industries in the economy that led the economic growth of the country. It affects the performance of the global economy, improving the efficiency of other sectors across the entire scale of economic activity-referred to as catalytic benefits. Aviation enhances the worldwide transportation network, which makes it essential for global business and tourism. It contributes a major role in facilitating economic growth, mainly in developing countries. According to 2015 estimation of the catalytic contribution to global GDP and employment is shown in Figure 1.

The air transport industry generates a total of 65.5 million jobs globally and over 10 million people work directly for the industry itself. It also contributes around US $\$ 880$ billion a year to world GDP, taking into account direct, indirect and induced impacts-equivalent to $2.7 \%$ of global GDP according to the Air Transport Action Group [11] [12]. This report further shows that Air travel carries $35 \%$ of world trade by value of $\$ 6.0$ trillion worth in 2016 . On average, aviation jobs 4.4 times more productive than other jobs in the economy. When considering the scope of the industry, it was estimated that 1303 airlines fly 31,717 aircraft on 45,091 routes between 3759 airports in airspace managed by 170 air navigation service providers. Approximately, 57\% of world tourists travel to their destinations by using air transportation. Then, the estimated growth in air transport will support around 97.8 million jobs and $\$ 5.7$ trillion in economic activity in 2036.

Figure 2 below shows an interaction between the relationship between the economy and the air transportation system. The model sets up the external relationship between the economy (shown in the upper left corner) and the air transportation system (shaded in gray on the lower right). The economy motivates a travel requirement which create the demand for air transportation. The 
supply of services in the air transportation sector provides an effect of economic enabling that generate access to customers, markets, views and ideas as well as the generation of capital that collaboratively enable an enhanced economy.

The basic macro functionality of the air transportation system was illustrated by the inter relationship between supply, demand and the economy. The model further illustrates how the internal structure of the Air Transportation System (blue box) is based on the profitability of the airline industry. This internal feedback threads and loops lead to connect the demand that is generated for air travel sector with the revenue aspects of airlines as well as the supply aspects of the air transportation aspects. Airlines ensure to control the supply aspect of air transportation services by modifying the prices of the service offerings, networks of operations and schedules of services that lead to have a high level of impact on the demand aspect related to the air transportation services sector. As shown in dashed lines, Figure 2 shows the monetary relationship between the economy and the airline industry. Economy impacts on the viability of the airlines to secure capital equity and financial debt. Employment in airport industry and spending by the aviation in turn, have direct, indirect and induced impact on the economy.

Within this frame, the analysis of this relationship, searching for the existence of causality between them, it has been of interest of few researchers [22]. [23] proposes a virtuous cycle as shown in Figure 3 to illustrate the relationship between transportation and growth. Under this conception, air transportation in economic infrastructure leads to increased productivity in the private sector, which in turn leads to increased economic output. This increased economic output in turn leads to an increased tax base and tax revenues which create increased capacity to fund new infrastructure investment. This view echoes the views of [24] [25] [26] [27], and seems a more realistic assessment of the causation issue.

There are two major types of literatures examining the impact of air transportation. First, the literatures examining the direct, indirect and induced employment impact of air transportation. These literatures ignore the enabling effects. Secondly the literatures which attempt to assess the catalytic impact of air transportation. Analysis shows that there is a correlation between air travel and GDP growth, however the mechanisms behind this interaction differ from country to country.

\begin{tabular}{lll}
\hline $\begin{array}{l}\text { APEC ECONOMIES } \\
\begin{array}{l}\text { Air transport supports 29.1 million } \\
\text { jobs and \$1.5 trillion in GDP in the } \\
\text { APEC economies }\end{array}\end{array}$ & $\begin{array}{l}\text { SMALL ISLAND STATES } \\
\text { Air transport supports 1.4 million } \\
\text { jobs and \$25.3 billion in GDP in small } \\
\text { island states }\end{array}$ & $\begin{array}{l}\text { OECD COUNTRIES } \\
\text { Air transport supports 21.9 } \\
\text { million jobs and \$1.9 trillion in } \\
\text { GDP in the OECD }\end{array}$ \\
$\begin{array}{l}\text { EUROPEAN UNION } \\
\begin{array}{l}\text { Air transport supports } 8.8 \text { million } \\
\text { jobs and \$708 billion ( } € 621 \text { billion) in } \\
\text { GDP in the EU28 }\end{array}\end{array}$ & $\begin{array}{l}\text { Air transport supports 38 million } \\
\text { jobs and \$561 billion in GDP in } \\
\text { developing countries }\end{array}$ &
\end{tabular}

Figure 1. Catalytic impact of air transportation on economic growth. Source: ATAG 2015. 


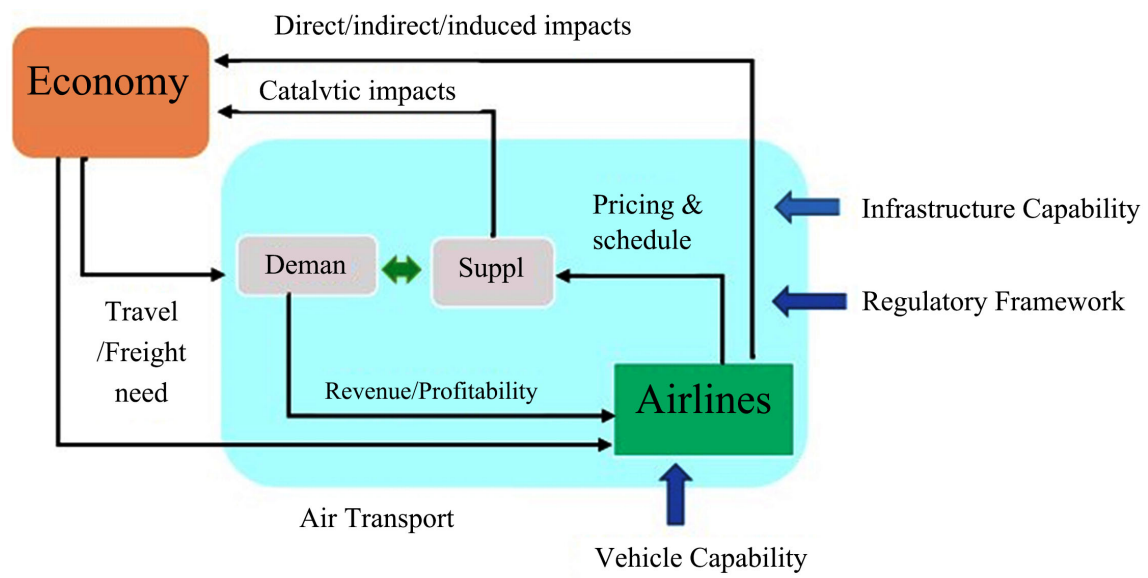

Figure 2. Feedback-based interaction between air transportation system and an economy. Source: Adapted from [21].

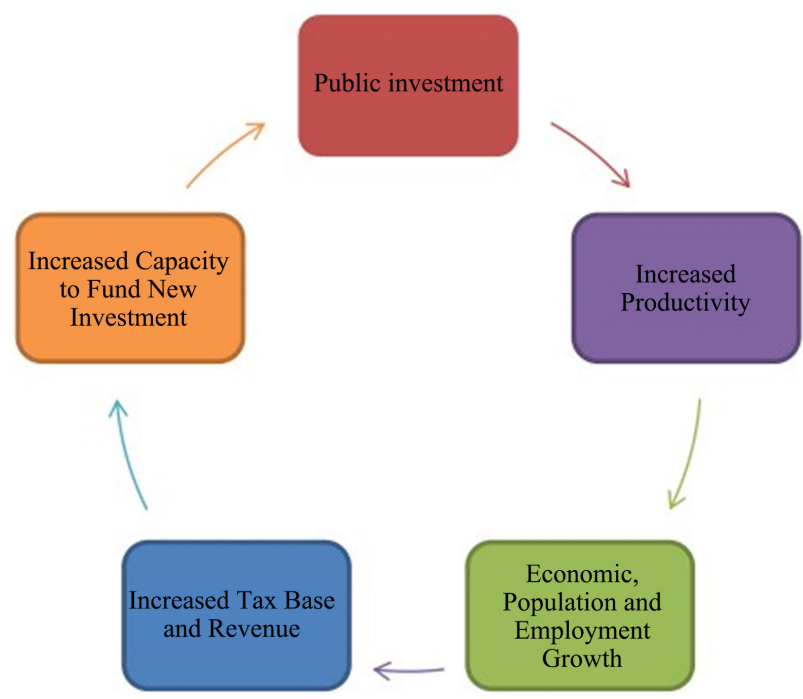

Figure 3. Virtuous cycle of transport in the economy. Source: Spohr et al. 2012.

\section{Methodology}

A systematic literature review (SLR) approach was used in this paper. SLR is a quasi-scientific analysis and it was initiated in the 1990s. It was primarily used in the research field of medicine, physical sciences such as systems engineering, and recently in social sciences discipline such as management, marketing, and strategic innovation. The SLR method differs from meta-analysis that seek to find common parameter values across studies or moderator variables which can be used to explain differences in the values found. In this study, researcher focused on output of journal as well as the value of publications. Practicality of a piece of research depends on its acceptance and the use of citation counts. According to [28] [29], systematic reviews should comprise a sub section on the methodology used and providing a clear-cut explanation of how the study was conducted.

This study differs from historical literature reviews of air transportation and it 
basically seeks to adopt a clear systematic approach to reduce prejudice through widespread bibliographical searches of published studies in developed and developing countries. Overwhelming literature on air transportation are available specially based on developed countries. But, scope of this study is limited to only publications written in English, and this study utilize only papers published in academic journals excluding books, chapters of books, conference proceedings, thesis publications. All literatures are summarized in the following headings and the corresponding findings are interpreted.

\section{Methodological Aspect of Assessing Impact of Air Transportation}

In literature, there are mainly three methods were used to assessing the economic impact of air transportation. These include:

- Effects on consumer and producer surplus (aggregate economic welfare) which is the focus of cost benefit analysis, this approached is applied to policies or projects;

- Microeconomic effect e.g. enterprise or household level productivity effects; and

- Macroeconomic effects e.g. contributions to GDP, investment or employment, and the spatial patterns of economic activity [17].

The approach to measuring of benefits and costs in a project appraisal is mainly a cost benefit analysis (CBA) approach which looks into direct effects of air transport investment for example, time savings, user charges, operating costs, and externalities. Most of the studies in European countries employ a CBA approach to estimate economic returns from air transport investment. To date there is no agreed consensus about how indirect effects of air transport infrastructure are treated. The most revealing evidence on this topic comes in the form of macro-econometric models which measure the effects of transport investment on productivity or output growth. This is due to the difficulty in differentiating the indirect effects of the direct effects while avoiding double counting.

\section{Search Measure for Papers of Air Transportation}

To find out papers related to air transportation, the keywords required to seem in the title, abstract and keywords of the of the research article. Simultaneously, the search took in the following aspect of publications i.e., 1) Type of the article i.e. whether the article is in journals, conferences, trade publications, book series, reports, etc.; 2) Type of the document, for example, whether document is a conference paper, review report, case study, book review, etc.

\section{Selecting the Databases}

When selecting journals and articles, different databases of air transportation which include Google scholar; ISI Web of Knowledge were selected from different publishers such as Thomson Reuters, Scopus from Elsevier, Science direct EconLit, Emerald Management Reviews, Business Source Elite. Initially, difficulties were found when searching the keyword "air" and/or "transport". The word "air" is used in many area of research such as medicine, biology and chemistry. Similarly, when searching the keyword "transport" given its highly generalized 
use. Therefore, this study chose to define different keywords such as Aviation, transportation, airport and growth etc., the words were chosen based on the American Economic Association (AEA) which produces the JEL Classification Codes Guide (Journal of Economic Literature). This provides mostly widely used set of keywords in social science research. Secondly, we also use "aviation", "aircraft" and "air traffic" as keywords. Finally, keywords such as air transport, air transportation, aircraft, aviation, airport, airline, airplane, air traffic, air travel, and aerospace were included.

\section{Analysis of Literature Review}

Findings of this study demonstrate a wide variety of research topics relating to the aviation, tourism and economic growth. Accordingly, 57 refereed journal articles were selected in the field of air transportation and economic growth. These 57 refereed articles were organized in following aspects.

\section{Evolution of the Academic Articles on Air Transportation}

Figure 4 shows, over the period, the number of publications per yearly has more than tripled. In particular, during the period 2012-2018, the number of publications has increased significantly, representing $45.37 \%$ of the total publications analyzed. This shows the growing importance of the topic on air transportation in recent years.

This study evaluated journals in the category of "Transportation" in the databases on Google scholar and ISI Web of Knowledge. Analysis found that during the last decade, the number of journals relating to the air transportation has increased by around 50\% as shown in Figure 4. Similarly, the increased number of journals can be indicative of a greater interest of a wider range of disciplines in the topics; e.g. some of the newer journals have a greater focus, such as Journal of Air transport management and Transport Geography and the demise of Transportation Planning Journal as shown in Figure 5.

\section{Most Productive and Most Frequently Cited Journals}

This section investigates which journals are the most productive and most often cited in this study, regarding to the topic addressed in this SLR, taking into account the 57 articles obtained from the systematic literature review and their corresponding ranking. As shown in Figure 6, the Journal of Air Transport Management (United Kingdom) is in first position, with 390 citations, and it is also the most specific journal in terms of air transport. On the other hand, Citation counts are higher for journals such as Journal of Transport Geography (130), Journal of Transport Economics and Policy (168).

\section{Study Areas of Papers on Air Transportation}

Abstract text of each paper was categorized according the key themes. A total of eight main themes were identified:

1) Aviation market: costs, carriers and charter services, regional routes;

2) Airports: capacity, carrier services, routes, passenger experiences;

3) Sustainable development: climate changes, emissions, tourism policies, aviation policies; 


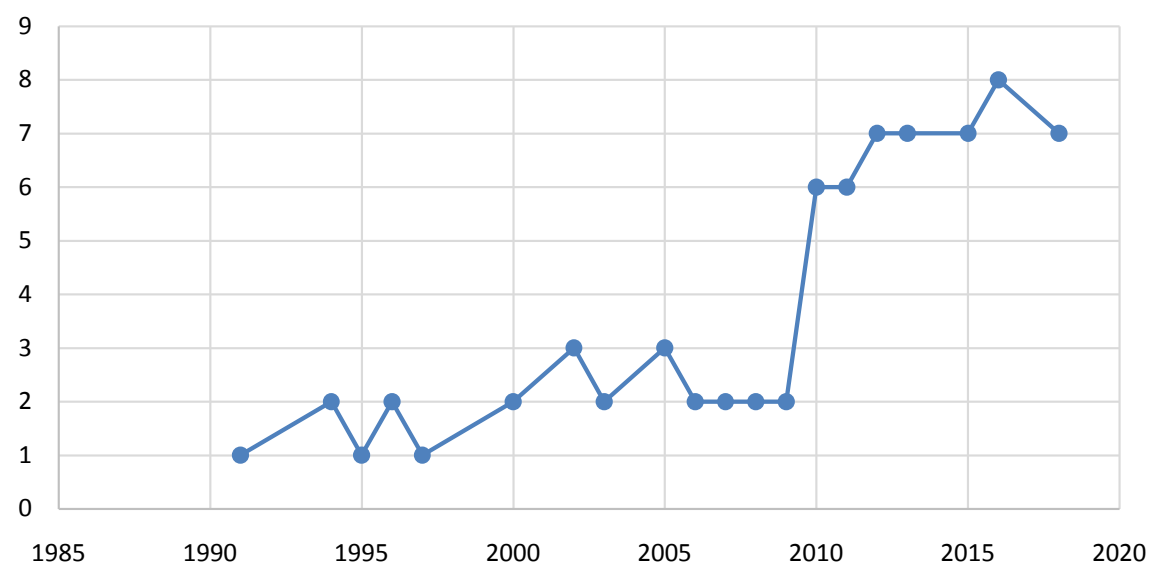

Figure 4. List of papers published in air transportation and growth over 1992-2018.

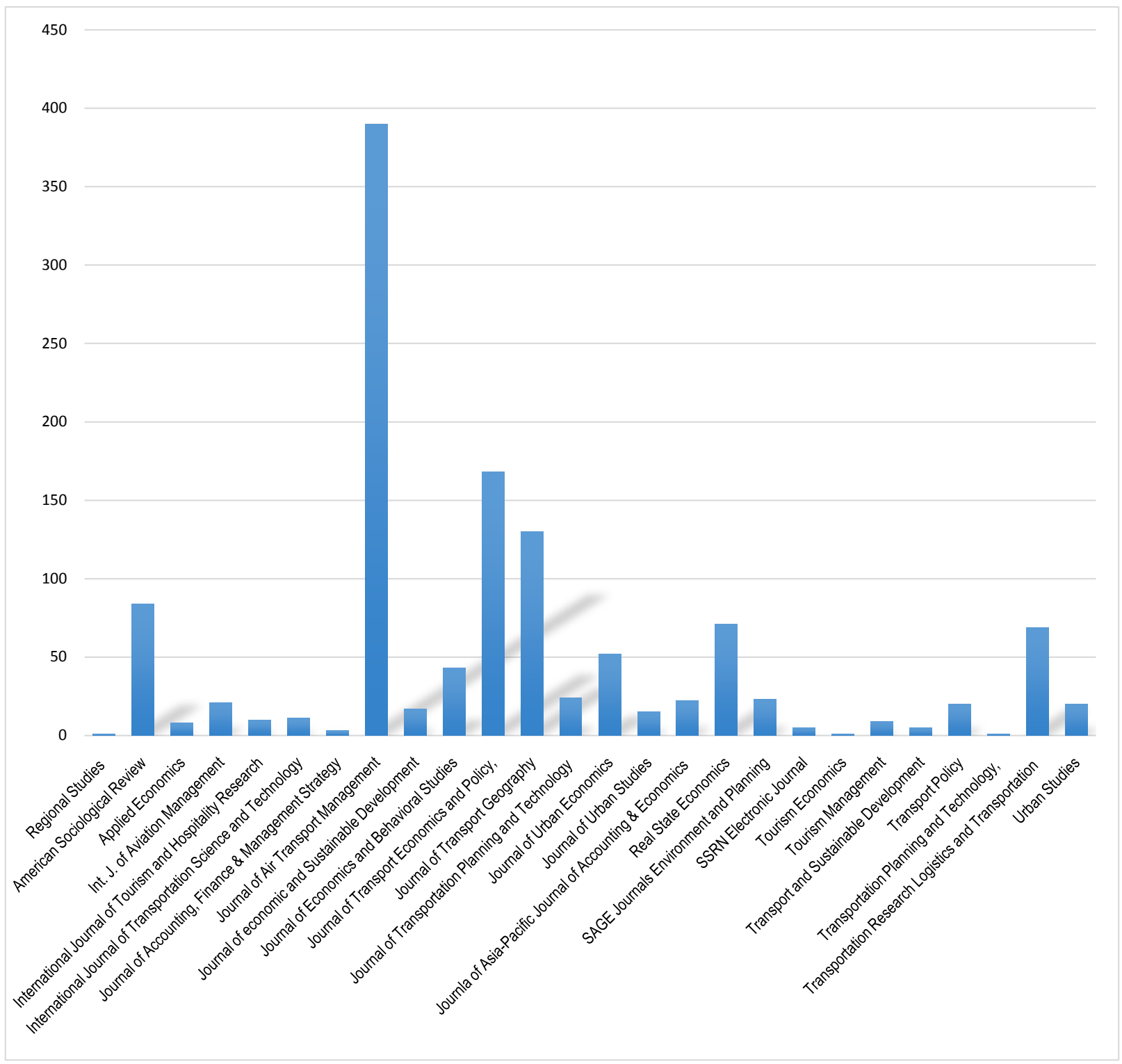

Figure 5. List of selected refereed journals. 


\begin{tabular}{|c|c|}
\hline Name of the Journal & Sum of Citation \\
\hline Regional Studies & 1 \\
\hline American Sociological Review & 84 \\
\hline Applied Economics & 8 \\
\hline Int. J. of Aviation Management & 21 \\
\hline International Journal of Tourism and Hospitality Research & 10 \\
\hline International Journal of Transportation Science and Technology & 11 \\
\hline Journal of Accounting, Finance \& Management Strategy & 3 \\
\hline Journal of Air Transport Management & 390 \\
\hline Journal of economic and Sustainable Development & 17 \\
\hline Journal of Economics and Behavioral Studies & 43 \\
\hline Journal of Transport Economics and Policy & 168 \\
\hline Journal of Transport Geography & 130 \\
\hline Journal of Transportation Planning and Technology & 24 \\
\hline Journal of Urban Economics & 52 \\
\hline Journal of Urban Studies & 15 \\
\hline Journal of Asia-Pacific Journal of Accounting \& Economics & 22 \\
\hline Real State Economics & 71 \\
\hline SAGE Journals Environment and Planning & 23 \\
\hline SSRN Electronic Journal & 5 \\
\hline Tourism Economics & 1 \\
\hline Tourism Management & 9 \\
\hline Transport and Sustainable Development & 5 \\
\hline Transport Policy & 20 \\
\hline Transportation Planning and Technology & 1 \\
\hline Transportation Research Logistics and Transportation & 69 \\
\hline Urban Studies & 20 \\
\hline
\end{tabular}

Figure 6. Number of cited articles whose title includes the keyword "air-transportation".

4) Airlines: networks, low-cost services, passengers;

5) Alliances: safety regulations, service quality, marketing;

6) Air transport demand;

7) Tourism destinations: air transport and tourism case studies;

8) Air transportation and economic growth.

\section{Study Method of Assessing the Papers on Air Transportation}

There are number of economic specifications can be identified in the modelling of the effects of transport infrastructure investment. They are the 1) Production Function approach (PFA), 2) the Multivariate Approach (MA) and, 3) the Vector Auto Regressive (VAR) approach.

As shown in Figure 7, most of the studies are relatively different due to using different data set, methodological approach, economic development level of the 
study region, and analyzing different time periods. Most of the analyses are based on production function approach. A few studies are available using Vector Auto Regressive (VAR) approach as shown in Figure 7. Interestingly, most of the literature on causality analysis between air transport and economic growth focuses on high-income countries (with often matured aviation markets). Generally, this study tries to fill the existing gaps in terms of identifying the determinants of air transport demand. Then this review proposes a new approach to examine the dynamic relationship between air transportation and economic growth, by means of a non-linear methodology. Applying this new approach enable to contrast these new results with those obtained by the classic linear methodology.

\section{Origin of the Authors}

The origin of each of the authors was analyzed in order to see the spatial distribution and to study where else the existing research topic has been given consideration.

Figure 8 show the 16 countries in which the topic of air transportation and growth has been studied. Among the countries included in this study, the United States dominated, representing $49 \%$ of the authors, out of a total of 57 articles included in the literature review. The countries belonging to the European Union with the largest proportion of authors are the United Kingdom (12\%) and the Netherlands (6.2\%).

\section{Causality Linkage of Papers on Air Transportation}

Empirical results as shown in Appendix 1 suggesting bi-directional causality between air transport and economic growth which are limited to that context. In contrast, causality results from middle-income countries such as Brazil and South East Asian showed strong causality run from economic growth to air transport but weak causality run from air transport to economic growth. Most importantly, there is no literature on a causal analysis between air transport and economic growth for low-income countries (with potential for very strong growth of air transport demand), which is a fundamental gap in context appears to matter to these relationships.

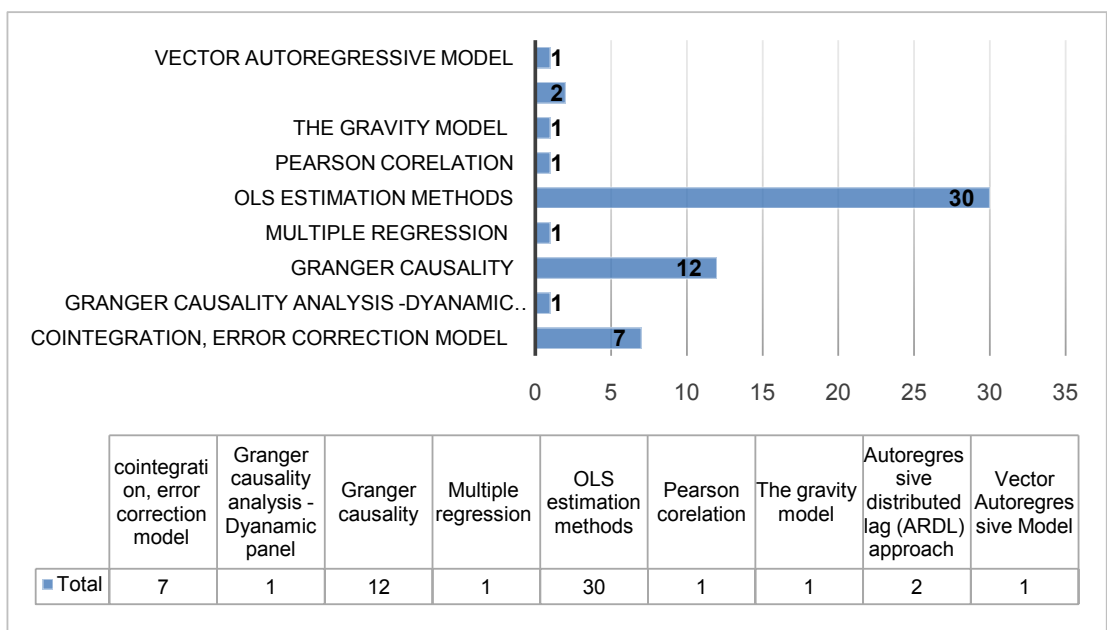

Figure 7. Methodological approaches identified. 


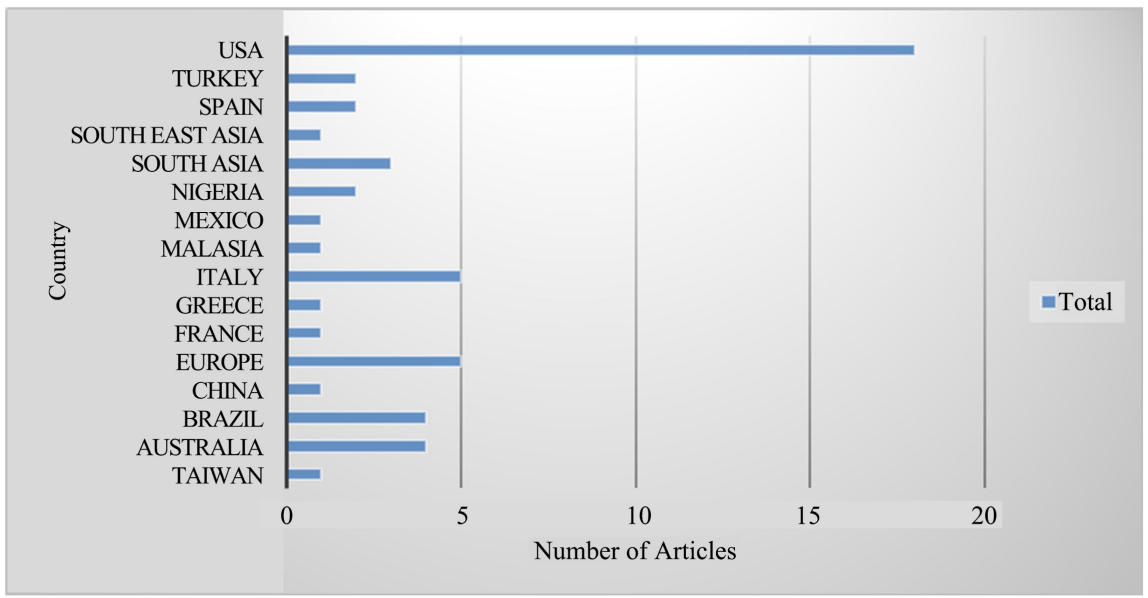

Figure 8. Literature on air transportation and growth.

Due to different inherited economic features of various countries/regions, the sensitivities of change of these variables to each other could also vary. Therefore, studies should also need to conduct on the relationship between air transport demand and economic growth in the specified region, like South Asia (see Appendix 1).

\section{Results/Findings}

Our review of the literature, summarized in this paper, on the impact of air transport improvements on economic growth and development in a country has found a large measure of agreement between researchers (all from developed countries) on this topic. The main findings are summarized as follows:

- This study employed the count of the papers published between 1992 and 2018 on the topics in the air transportation, and structured these papers by methodological approach. The study found that there is evidence of a growing interest by academics in the field of air transportation management, especially since 2010 , with the output of articles on air transportation has increased dramatically in 2010, 2012, 2015 with a large proportion of the studies on air transport growth and management.

- In developed countries like Sri Lanka that have a high quality, well-connected transportation network, further investment in that infrastructure on air transportation will not on its own result in economic growth. Evidence of effect of transport infrastructure investment on economic growth is limited. The high rates of return to transport investment claimed by some past studies are most likely the result of statistical correlation or other model specification issues.

- The incremental economic gains from investment in transport infrastructure in developed economies, above that needed to respond to demand, are likely to be modest. Possibly, there is a range within which most of the developed economies may experience greater gains than developing countries, but solid evidence to this effect is lacking. 
- This paper considered a number of the themes that have emerged from this body of research, and made a number of important conclusions: The discussion of the texts demonstrates the plethora of empirical arguments on the topic. While there is no consensus among the authors on the scale and magnitude of these effects, a lot of the variation in results can arise because of differences in spatial aggregation, the type of data used and model specification.

- Empirical results suggesting bi-directional causality between air transport and economic growth which are limited to that context. In contrast, causality results from middle-income countries like Brazil and South East Asian showed strong causality run from economic growth to air transport but weak causality run from air transport to economic growth. Most importantly, literatures are lacking on a causal analysis between air transport and economic growth for low-income countries, which is a fundamental gap in context appears to matter to these relationships.

- When reviewing the existing studies most of the studies showed that there is bi directional relationship between air transport demand and economic growth. Therefore, the link between transport and the economy are now become more complex and the strength of the various linkages becomes less clear cut.

\section{Conclusions}

In spite of the fact that air transportation is a key element in the economic growth, it must be mentioned that no specific literature review article in the aviation sector has considered. Therefore, the paper has tried to bridge this gap and conduct a systematic literature review (SLR), using ABDC list journals which are ranked on $A^{*}, A$ or B, published in period 1992-2018. This review enabled us to classify international academic articles corresponding to the topic on Air transportation. The most frequently cited journals were examined, starting with a total of 1000 articles, after the selected articles were refined, a sample of 57 articles published between 1992 and 2018 were analyzed. The first conclusion of this study that we can mention on is that the research topic on air transportation and growth is one of growing interests, even though the total number of articles is very low in terms of total value. The main contribution of this study for academic audience can be found in describing air transport and growth research patterns. Research areas such as air transport demand, passenger experiences, airports and airlines are overlapping topics for both growth and air transport researchers. Most of the articles obtained after the preliminary search have been primarily related to the direct and indirect impact of transportation, and only a few articles are based on catalytic impact on air transportation. The most productive journal in terms of both the total number of articles included and the total number of citations was the Journal of Air Transport Management. In second place is Journal of transport economic and policy, with 130 citations. It 
should be stressed that the SLR carried out in this study offers an opportunity for future lines of research with a more economic-oriented focus, as the study has shown that air transport, as an essential topic in the field of economic growth, provides little academic literature related to policy aspect.

This study has a number of limitations: first that not all related academic journals were not taken into consideration, since only those on the ABDC list. A second limitation in this study is that this study examined only the journals which were published in English.

\section{Conflicts of Interest}

This statement is to certify that all Authors have seen and approved the manuscript being submitted. We warrant that the article is the Authors' original work. We warrant that the article has not received prior publication and is not under consideration for publication elsewhere. On behalf of all Co-Authors, the corresponding Author shall bear full responsibility for the submission. We attest to the fact that all Authors listed on the title page have contributed significantly to the work, have read the manuscript, attest to the validity and legitimacy of the data and its interpretation, and agree to its submission to the Journal of Advanced transportation. All authors accept that the Editor-in-Chief's decisions over acceptance or rejection:

1) Dr Wasanthi Madurapperuma, Senior Lecturer, University of Kelaniya, Sri Lanka.

2) Mr. Ruwan Higgoda, Air Traffic Controller, AIA Sri Lanka.

\section{Funding Statement}

This work will be supported by Research and publication division, University of Kelaniya.

\section{References}

[1] The World Bank (2008) The World Bank World Development Indicators Online. http://documents.worldbank.org/curated/en/587251468176971009/World-develop ment-indicators-2008

[2] Van de Vijver, F.J.R. (2015) Methodological Aspects of Cross-Cultural Research. In Gelfand, M., Hong, Y. and Chiu, C.Y., Eds., Handbook of Advances in Culture and Psychology, Oxford University Press, New York, Vol. 5, 101-160.

[3] Ozcan, I.C. (2013) Air Passenger Traffic and Local Employment: Evidence from Turkey. European Journal of Transport and Infrastructure Research, 13, 336-356.

[4] Ozcan, I.C. (2014) Economic Contribution of Essential Air Service Flights on Small and Remote Communities. Journal of Air Transport Management, 34, 24-29. https://doi.org/10.1016/j.jairtraman.2013.07.005

[5] Brida, J.G., Rodríguez-Brindis, M.A., Lanzilotta, B. and Rodríguez-Collazo, S. (2016) Testing Linearity in the Long Run Relationship between Economic Growth and Passenger Air Transport in Mexico. International Journal of Transport Economics, 43, 437-450.

[6] Dharmawan, I. (2012) The Effect of Air Transport to Economic Development in 
Indonesia. PhD Dissertation, Erasmus University, Erasmus.

[7] Fernandes, E. and Pacheco, R.R. (2010) The Causal Relationship between GDP and Domestic Air Passenger Traffic in Brazil. Transportation Planning and Technology, 33, 569-581. https://doi.org/10.1080/03081060.2010.512217

[8] Hakim, M.M. and Merkert, R. (2016) The Causal Relationship between Air Transport and Economic Growth: Empirical Evidence from South Asia. Journal of Transport Geography, 56, 120-127. https://doi.org/10.1016/j.jtrangeo.2016.09.006

[9] Bourguignon, F. and Darpeix, P.-E. (2016) Air Traffic and Economic Growth: The Case of Developing Countries. Working PAPER No. 2016-09, Paris School of Economics. https://halshs.archives-ouvertes.fr/halshs-01305412/document

[10] Juan, G., Daniel, B. and Sandra, Z. (2016) Dynamic Relationship between Air Transport and Economic Growth in Italy: A Time Series Analysis. International Journal of Aviation Management, 3, 52-67.

[11] Munnell A.H. (1992) Policy Watch: Infrastructure Investment and Economic Growth. The Journal of Economic Perspective, 6, 189-198.

https://doi.org/10.1257/jep.6.4.189

[12] ATAG (2016) Facts and Figures. https://www.aviationbenefits.org/media/149654/abbb2016_global-summary_web.p df

[13] ATAG (2005) The Air Transport Industry and Its Economic Impacts.

[14] ATAG (2005) The Economic and Social Benefit of Air Transport by Oxford Economic Forecast Brochure (OEF).

[15] Chang, Y.-H. and Chang, Y.-W. (2009) Air Cargo Expansion and Economic Growth: Finding the Empirical Link. Journal of Air Transport Management, 15, 264-265. https://doi.org/10.1016/j.jairtraman.2008.09.016

[16] Chi, J. and Beak, J. (2013) Dynamic Relationship between Air Transport Demand and Economic Growth in the United States: A New Look. Transport Policy, 29, 257-260. https://doi.org/10.1016/j.tranpol.2013.03.005

[17] Lim, C. (1997) Review of International Tourism Demand Models. Annals of Tourism Research, 24, 835-849. https://doi.org/10.1016/S0160-7383(97)00049-2

[18] Dimitriou, D and Sartzetaki M. (2018) Assessing Air Transport Socio-Economic Footprint. International Journal of Transportation Science and Technology, 7, 283-290. https://doi.org/10.1016/j.ijtst.2018.07.001

[19] Tolcha, T.D, (2017) Air Transport Demand and Economic Growth in Ethiopia (Cointegration and Causality Analysis). Master Thesis, Molde University College, Molde.

https://brage.bibsys.no/xmlui/bitstream/handle/11250/2465753/master_tolcha.pdf?s equence

[20] Bright, W.A. and Habte, M. (2015) Services Exports for Growth and Development: Case Studies from Africa. Air Transport Services: A Case Study of Ethiopia.

[21] Hansman, R.J. (2005) The Impact of Information Technologies on Air Transportation. AIAA Aerospace Sciences Conference, Reno, 10-13 January 2005.

http://citeseerx.ist.psu.edu/viewdoc/download?doi=10.1.1.455.8075\&rep=rep1\&type $=\mathrm{pdf}$

[22] Green, R. (2007) Airports and Economic Development. Real Estate Economics, 35, 91-112. https://doi.org/10.1111/j.1540-6229.2007.00183.x

[23] Spoehr, J. Burgan, B. and Molloy, S. (2012) Public Investment in Productivity and Economic Growth: The Role and Contribution of Debt Funding. Australian Insti- 
tute for Social Research.

[24] Eddington, S.R. (2006) The Eddington Transport Study-The Case for Action. Sir Rod Eddington's Advice to Government. HM Treasury.

[25] Munnell, A.H. (1992) Policy Watch: Infrastructure Investment and Economic Growth. The Journal of Economic Perspective, 6, 189-198. https://doi.org/10.1257/jep.6.4.189

[26] Denyer, D. and Neely, A. (2004) Introduction to Special Issue: Innovation and Productivity Performance in the UK. International Journal of Management Reviews, 5, 131-135. https://doi.org/10.1111/j.1460-8545.2004.00100.x

[27] Duncan (2009) Transport Interventions-Towards Value for Money over Time. New Zealand Association of Economists Conference, Wellington, 1-3 July 2009.

[28] Brida, G., Lanzilotta, B., Brindis, M. and Rodríguez, S. (2014) Long-Run Relationship between Economic Growth and Passenger Air Transport in Mexico.

[29] Ginieis, M., Sánchez-Rebull, M.V. and Campa-Planas, F. (2012) Analysis Using Systematic Literature Review Methodology. Journal of Air Transport Management, 19, 31-35. https://doi.org/10.1016/j.jairtraman.2011.12.005

\section{Appendix 1: Summary of Literature on Causality of Air Transport and Economic Growth}

\begin{tabular}{|c|c|c|c|}
\hline Authors & Study area & Causality type & Causality direction \\
\hline Brida, Daniel, Sandra, 2016 & Italy & Uni-directional & Air transport GDP \\
\hline Hakim \& Merkert, 2016 & South Asia & Uni-directional & GDP air passenger traffic and air freight volumes \\
\hline Alexander, Saheed, S. \& Iluno, 2015 & Nigeria & Uni-directional & Air transport economic growth \\
\hline $\begin{array}{l}\text { Baker, Douglas, Merkert, Rico, } \\
\text { Kamruzzaman, Md, } 2015\end{array}$ & Australia & Bi-directional & Regional economic growth regional air transport \\
\hline Brida, Lanzilotta, Brindis, \& Rodríguez, 2014 & Mexico & Bi-directional & Air transport Economic growth \\
\hline Chi \& Baek, 2013 & United States & Bi-directional & Air transport economic growth \\
\hline Mukkala \& Tervo, 2013 & $\mathrm{EU}$ & Uni-directional & Airline traffic \& economic growth \\
\hline Dharmawan's, 2012 & Indonesia & Bi-directional & Airline traffic frequency \& economic growth \\
\hline Florida et al., 2012 & United States & Bi-directional & Airport effects \& Economic Development \\
\hline Doganis, 2010 & Brazil & Bi-directional & Air traffic \& Economic growth \\
\hline Pacheco, 2010 & Brazil & Bi-directional & Economic growth \& National airline passenger transport \\
\hline Marazzo, Fernandes \& Scherre, 2009 & Brazil & Uni-directional & Economic growth National Airline \\
\hline Chang, \& Chang, 2009 & Taiwan & Bi-directional & Air cargo Economic growth \\
\hline Yao and Yang, 2008 & China & Bi-directional & Airport Development \& Economic growth \\
\hline Green, 2007 & Taiwan & Bi-directional & Air transportation \& economic growth \\
\hline Brueckner, 2003 & United States & Bi-directional & Air traffic \& Employment \\
\hline Bowen, 2000 & Italy & Bi-directional & Freedom to airline sector \& airport development \\
\hline
\end{tabular}

Source: Compiled from respective papers, 2018. 